\title{
TROCAS GASOSAS DE CAFEEIROS (Coffea arabica L.) E SERINGUEIRAS (Hevea brasiliensis Muell. Arg.) EM DIFERENTES SISTEMAS DE CULTIVO NA REGIÃO DE LAVRAS, MG ${ }^{1}$
}

Cláudio Roberto Meira de Oliveira², João Paulo Rodrigues Alves Delfino Barbosa ${ }^{3}$, Angela Maria Soares ${ }^{4}$, Luiz Edson Mota de Oliveira ${ }^{4}$ e Renato Luiz Grisi Macedo ${ }^{5}$

\begin{abstract}
RESUMO - O uso de sistemas de cultivo agrícola que favorecem a conservação dos recursos naturais e a diversidade de produção representa uma alternativa para produtores que visam menores custos em uma produção sustentável. Dentre esses sistemas de cultivo, destaca-se o sistema de consórcio entre cafeeiros e seringueiras, que tem sido estudado na região sul de Minas Gerais. Nesse contexto, avaliaram-se características de trocas gasosas, fluorescência da clorofila e relações hídricas de cafeeiros e seringueiras, em monocultivo e consórcio, na fase de implantação dos cultivos, com o objetivo de verificar o comportamento dessas espécies em diferentes sistemas de cultivo. Os resultados apontaram que um ambiente caracterizado por níveis de radiação e temperatura menores favorece as trocas gasosas do cafeeiro, enquanto maior disponibilidade hídrica e valores elevados de radiação são favoráveis ao desenvolvimento da seringueira quando em sistemas consorciados.
\end{abstract}

Palavras-chave: Heveicultura, sistemas agroflorestais, cafeicultura e fotossíntese.

\section{GAS EXCHANGE IN COFFEE (Coffea arabica L.) AND RUBBER TREE (Hevea brasiliensis Muell. Arg.) IN DIFFERENT CROP SYSTEMS IN LAVRAS, MG}

\begin{abstract}
Crop systems that improve conservation of natural resources and diversity of production is a promising practice for farmers seeking low costs and a sustainable agriculture. The coffee - rubber tree intercropping has been studied in the south of Minas Gerais - Brazil. Within this context, the objective of this work was to evaluate the characteristics gas exchange, chlorophyll fluorescence and water relations of coffee and rubber tree in both intercropping and monocroping systems, in the early stage of the plantation establishment. The results showed that the reduction in radiation levels and temperature promote gas exchange increase in coffee, while higher photosynthetic radiation values and soil water availability are favorable to rubber tree in intercropping systems.
\end{abstract}

Keywords: Coffee, Rubber tree, intercropping system and photosynthesis.

\footnotetext{
${ }^{1}$ Recebido em 05.10.2004 e aceito para publicação em 10.11.2005.

${ }^{2}$ Universidade Estadual da Bahia, Bahia - Campus XVI.

${ }^{3}$ Programa de Pós-Graduação em Agronomia - Fisiologia Vegetal - UFLA.

${ }^{4}$ Departamento de Biologia, setor de Fisiologia Vegetal - UFLA. E-mail: <amsoares@ufla.br>.

${ }^{5}$ Departamento de Ciências Florestais - UFLA.
} 


\section{INTRODUÇÃO}

Técnicas de produção agrícola, como rotação de culturas e consórcio entre plantas, têm sido bastante implantadas por agricultores que visam conciliar a conservação de recursos naturais a uma produção diversificada. Os sistemas agroflorestais podem ser considerados uma dessas técnicas (SCHALLER et al., 2003; PEETERS et al., 2003).

O consórcio entre cafeeiro e seringueira é um sistema agroflorestal que tem sido estudado, recomendado e utilizado com vantagens para ambas as culturas, em algumas regiões produtoras de café e borracha no Brasil (VENEZIANO et al., 1994; PEREIRA et al., 1998) e em outros países como Java (INSTITUT..., 1992). No sul de Minas Gerais, maior pólo produtor de café do mundo, o cultivo de cafeeiros e seringueiras em sistema de consórcio limita-se a pequenas áreas, muitas vezes destinadas à pesquisa. Entretanto, esse tipo de cultivo pode ser visto como uma alternativa promissora, pois consiste em uma forma de uso do solo capaz de promover sua proteção e recuperação, além de auxiliar a conservação dos recursos hídricos e possibilitar a diversificação da produção, favorecendo maior estabilidade econômica ao produtor, particularmente em casos de pequena propriedade (PEREIRA et al., 2000; SANTOS et al., 2000; FONTES, 2001).

Uma das vantagens do consórcio entre cafeeiros e seringueiras consiste na associação de espécies com diferentes exigências em termos de luminosidade. A seringueira é uma planta heliófita, eficiente na conversão de luz em carboidratos, que desenvolve em condições de alta luminosidade, umidade e temperatura (FURIA, 2000), enquanto o cafeeiro se mostra sensível a níveis de radiação solar mais elevados, típicos de dias de verão. Esse excesso de radiação pode saturar o aparelho fotossintetizante, causando fotoinibição e consequiente redução no crescimento e produção da planta (FREITAS et al., 2003). Entretanto, diversos autores, entre eles Fournier (1988), Peeters et al. (2003) e Da Matta (2004), apontaram menor produção do cafeeiro sob sombra que a pleno sol, em consequiência não somente da menor disponibilidade de radiação nesses cultivos, que afeta o padrão de crescimento das plantas, mas também das diferenças no manejo da cultura nesses ambientes. Tais observações reforçam a necessidade de estudos que enfoquem os efeitos de diferentes tipos de plantios que podem caracterizar uma condição de sombreamento

R. Árvore, Viçosa-MG, v.30, n.2, p.197-206, 2006 no comportamento fotossintético e, conseqüentemente, na produção dos cafeeiros.

A manutenção de um microclima favorável ao crescimento e produção contínua do cafeeiro pode ser ainda considerada fator interessante para a sua produção no consórcio com seringueira, uma vez que nessas condições a descontinuidade da produção, característica típica de cafeeiros a pleno sol, pode ser reduzida ou até mesmo eliminada. Além disso, as plantas apresentam crescimento mais vigoroso e ficam menos suscetíveis à ocorrência de intempéries, como veranicos e geadas (JARAMILLO-ROBLEDO e VALENCIAARIZTIZÁBAL, 1980; FOURNIER, 1988; RENA et al., 1998; Da MATTA, 2004). São também apresentados como aspectos benéficos dos plantios consorciados a produção de ramos com internódios mais longos, o que influencia a qualidade e tamanho de frutos; o aumento no número de ramos plagiotrópicos; a diminuição da incidência de plantas daninhas e da população de pragas; e a melhoria das características físico-químicas do solo (FOURNIER, 1988; SCHALLER et al., 2003).

Neste trabalho foram avaliadas características biofísicas em cafeeiros e seringueiras em diferentes sistemas de cultivo durante a estação seca e a estação chuvosa, com o objetivo de verificar a hipótese de que plantas em consórcio podem apresentar respostas fisiológicas distintas daquelas de plantas em monocultivo, devido às modificações do microclima da área e a efeitos competitivos entre as plantas.

\section{MATERIAL E MÉTODOS}

O estudo foi conduzido de outubro de 2000 a agosto de 2001, na área experimental da Fazenda Vitorinha, em Lavras, região sul de Minas Gerais, localizada a $918 \mathrm{~m}$ de altitude, latitude $21^{\circ} 14^{\prime} \mathrm{S}$ e longitude $45^{\circ}$ 00' W. A temperatura média anual do ar dessa região é de $19,4^{\circ} \mathrm{C}$ e as médias anuais de temperatura, máxima e mínima, de 26,1 e $14,8^{\circ} \mathrm{C}$, respectivamente, com precipitação anual de $1.529,7 \mathrm{~mm}$ (BRASIL, 1992). Segundo a classificação climática de Köppen, o clima da região é do tipo Cwa, com duas estações definidas: seca (abril a setembro) e chuvosa (outubro a março).

Foram utilizados plantios consorciados de café (Coffea arabica L.), cv Rubi, com seringueira (Hevea brasiliensis Muell Arg.) e monocultivo. Nesses plantios, os cafeeiros foram implantados em 1997 e as seringueiras, 
em 1999. Foram avaliadas plantas de café e seringueira nos diferentes sistemas de cultivo (consórcio e monocultivo), constituindo cinco tratamentos, apresentados nos parágrafos subseqüentes.

O primeiro tratamento refere-se ao consórcio em que as seringueiras, clone PB235, foram plantadas como quebra-vento, margeando os talhões da lavoura cafeeira (consórcio tipo margem). No segundo tratamento, as árvores de seringueira, clone PB235, foram plantadas em linhas duplas perpendiculares ao sentido das ruas de cafeeiros (consórcio tipo renque), sendo a distância entre os renques consecutivos de 20,0 m. Os demais tratamentos se referem a plantios em monocultivo de cafeeiros e seringueiras, clones PB235 e GT1. As plantas de café avaliadas nos consórcios foram as situadas na linha vizinha à planta de seringueira avaliada.

Para as seringueiras plantadas em linha, como quebra-vento para as plantas de café, o espaçamento foi de 3,0 m entre plantas, sendo de 0,75 $\mathrm{m}$ a distância entre a linha de seringueiras e a primeira rua de cafeeiros. No consórcio denominado tipo renque, o espaçamento foi de 4,0 x 3,0 m (entre plantas e entre linhas). Em relação ao monocultivo de seringueira, em ambos os clones avaliados o espaçamento utilizado foi de 3,0 x 7,0 m (entre plantas e entre linhas). Tanto no monocultivo quanto no consórcio, o espaçamento entre as plantas de café era de 2,0 x 0,75 m.

As avaliações de trocas gasosas foram realizadas utilizando-se um analisador portátil de $\mathrm{CO}_{2}$ a infravermelho (ADC-LCA4- HODDESDON-UK). Avaliaram-se as seguintes características: fotossíntese líquida (A), condutância estomática (gs), densidade de fluxo de fótons fotossinteticamente ativos (DFFFA) e temperatura e umidade relativa da cubeta. A partir dos dados de umidade relativa e temperatura da cubeta, foram obtidos os valores do déficit de pressão de vapor da atmosfera (DPV). A eficiência fotoquímica do fotossistema II (razão Fv/Fm) foi determinada após pré-condicionamento das folhas ao escuro por $30 \mathrm{~min}$, para medição da fluorescência rápida “in vivo", por meio de um fluorômetro portátil (Plant Efficiency Analyser- Hansatech, King's Lynn, Nor Kfolk, UK).

Tanto as avaliações de trocas gasosas quanto as de eficiência fotoquímica do fotossistema II foram realizadas em quatro plantas de cada espécie, utilizandose uma folha por planta, em cada tratamento. Essas avaliações foram feitas entre 11 e 13 h em dias típicos, isto é, predominantemente claros, em intervalos de 20 a 40 dias, sempre em folhas completamente expandidas do terço médio do cafeeiro e de folhas maduras do terço médio da copa da seringueira. Em dias típicos da estação chuvosa (17/03/2001) e da estação seca (24/06/2001) foram também realizadas avaliações às 9 e 15 horas, para observar a variação diurna dessas características.

O potencial hídrico foliar ao amanhecer e ao meiodia solar foi avaliado em três plantas de cada espécie para cada tratamento, uma folha por planta, com o auxílio de uma bomba de pressão (Soil Moisture-Model 3005), nas datas das avaliações de trocas gasosas.

O delineamento experimental foi o inteiramente casualizado (DIC) com parcelas subdivididas no tempo, sendo os sistemas de plantio dispostos nas parcelas e as épocas nas subparcelas, com relação a todas as características avaliadas. A análise de variância foi feita utilizando-se o programa SISVAR, e a comparação de médias foi realizada pelo teste de Tukey a 5\% de probabilidade.

\section{RESULTADOS E DISCUSSÃO}

A média sazonal da densidade de fluxo de fótons fotossinteticamente ativos (DFFFA) foi maior na estação chuvosa em todos os tratamentos, atingindo valores entre 1.800 e $2.200 \mu \mathrm{mols} \mathrm{m} \mathrm{m}^{-2} \mathrm{~s}^{-1}$, enquanto na estação seca esses valores variaram entre 1.100 e $1.600 \mu \mathrm{mols}$ $\mathrm{m}^{-2} \mathrm{~s}^{-1}$ (Figura 1). O déficit de pressão de vapor (DPV - Figura 1) apresentou menor variação entre as estações em todos os tratamentos, sendo, ainda, os maiores valores verificados na estação chuvosa (2,5 e 3,1 kPa). Embora tenha sido observado tendência de aumento do DPV na estação chuvosa do monocultivo de seringueira (SM) no plantio consorciado (CM), de maneira geral os resultados da densidade de fluxo de fótons fotossinteticamente ativos e o déficit de pressão de vapor não revelam grandes diferenças de microclina nos sistemas de cultivo avaliados.

Essas constatações indicam que, na fase de desenvolvimento dos plantios estudada, as diferenças de arquitetura das espécies envolvidas não interferem nessas características microclimáticas. Segundo Monteith et al. (1991), a fase de desenvolvimento do sistema agroflorestal é um fator importante na determinação das características microclimáticas dos cultivos, sendo observado em um sistema já desenvolvido

R. Árvore, Viçosa-MG, v.30, n.2, p.197-206, 2006 
maior umidade do ar e diferenças na radiação incidente nos vários estratos do dossel da comunidade. Barradas e Fanjul (1986), em estudo de caracterização microclimática de plantios de cafeeiros sombreados e a pleno sol, mostraram diferenças entre as características microclimáticas dos cultivos, com maior conservação da umidade do ar nos plantios sombreados. Morais et al. (2003) verificaram reduções de até $90 \%$ da radiação solar global incidente em cafeeiros cultivados com feijão guandu. Segundo esses autores, esse elevado nível de sombreamento é responsável por maior manutenção da umidade do ar e do solo nos sistemas consorciados.

O potencial hídrico foliar antes do amanhecer, em geral, apresentou valores maiores que $-1,0 \mathrm{MPa}$ tanto na estação chuvosa quanto na estação seca, em todos os sistemas de cultivo (Figura 2). Em relação ao potencial hídrico ao meio-dia, os menores valores foram observados nos cafeeiros, tanto na estação chuvosa quanto na estação seca, sendo significativamente diferentes dos valores verificados antes do amanhecer, atingindo valores próximos de -3,0 MPa para essa espécie (Figura 2). Tanto no potencial hídrico obtido antes do amanhecer e ao meio-dia, não se observou diferença significativa entre os diferentes sistemas de cultivo.

Kumar e Tieszen (1980) afirmaram que o cafeeiro em condições de estresse hídrico apresenta valores de potencial hídrico em torno de -1,5 a-1,8 MPa. Segundo esses autores, tal condição hídrica é comumente encontrada nos horários de maior demanda evaporativa da atmosfera ( 11 - 15h), mesmo quando não há restrições de água no solo. Afirmaram também que essa faixa de potencial hídrico pode ser prejudicial ao cafeeiro, pois contribui para a redução da fotossíntese líquida, afetando, assim, a produção dessa cultura. Menores taxas fotossintéticas também foram observadas por Lima et al. (2002) em plantas de Coffea Canephora de 10 meses de idade, cultivadas em vasos e em casa de vegetação, nessa mesma faixa de potencial hídrico.

Fournier (1988) e Da Matta (2004) ressaltaram a importância do cultivo de cafeeiros sob sombra em locais onde o déficit hídrico é um fator limitante para o desenvolvimento e a produção satisfatória dos cafeeiros, já que as árvores cultivadas com os cafeeiros trazem vantagens quanto à manutenção da umidade do solo e à menor demanda evaporativa da atmosfera naquele microclima, contribuindo para a redução ou até mesmo eliminando o efeito do estresse hídrico. Entretanto, esse aspecto benéfico do plantio consorciado só se verifica quando a competição pela água no solo é insignificante. Tal condição pode ser alcançada com um manejo adequado da parte aérea, através de podas e de utilização de espécies que explorem diferentes camadas do solo (FURIA, 2000).

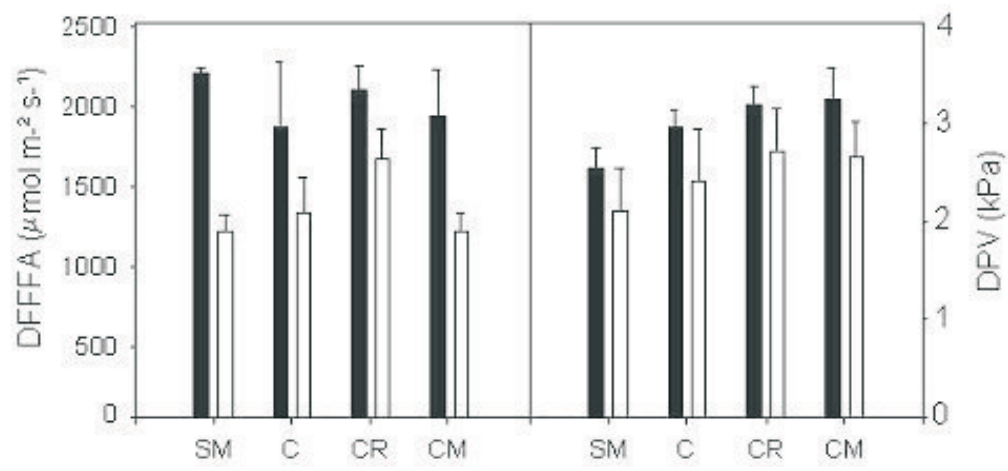

Figura 1 - Valores médios sazonais da densidade de fluxo de fótons fotossinteticamente ativos (DFFFA) e déficit de pressão de vapor (DPV) em plantas de seringueira em monocultivo (média dos clones GT1 e PB 235 - SM) e café em monocultivo (C), consórcio café/seringueira tipo renque (média das espécies - CR) e consórcio café/seringueira tipo margem (média das espécies - CM), referentes à estação chuvosa ( $\mathbf{\square})$ e à estação seca ( $\square$ ), às 12 horas. Cada barra corresponde à média \pm erro-padrão de 24 observações.

Figure 1 - Seasonal mean of midday photosynthetic photon flux density (DFFFA) and vapor pressure deficit (DPV) for monocropped rubber tree (clones GT1 e PB 2354 averages - SM) and coffee (C), alley cropping (average of species - CR) and hedge-row intercropping coffee/rubber tree (average of species - CM) for rainy ( $\square$ ) and dry $(\square)$ seasons. Bars correspond to the mean ( \pm standard error) of 24 replications.

R. Árvore, Viçosa-MG, v.30, n.2, p.197-206, 2006

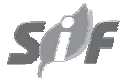




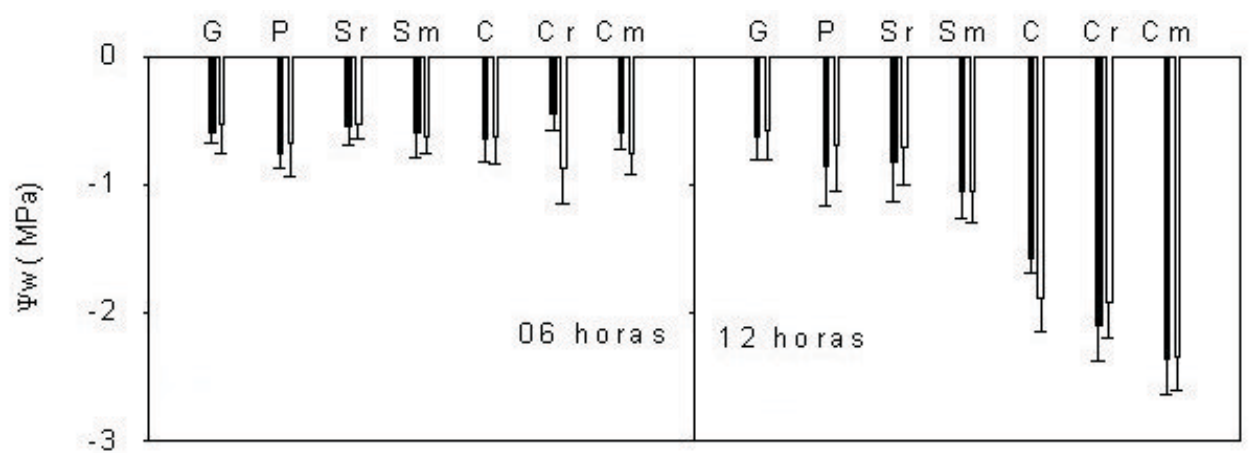

Figura 2 - Valores médios sazonais do potencial hídrico foliar $\left(\Psi_{\mathrm{w}}\right)$ ao amanhecer e ao meio-dia, referentes à estação chuvosa (घ) e à estação seca ( $\square$ ) em plantas de seringueira em monocultivo (P - clone PB 235 e G - clone GT1), café em monocultivo (C), café e seringueira consorciados em renque ( $\mathrm{Cr}$ e $\mathrm{Sr}$ ), e café e seringueira consorciados em margem $(\mathrm{Cm}$ e Sm). Cada barra corresponde à média ( \pm erro-padrão) de 20 observações.

Figure 2 - Seasonal mean predawn and midday leaf water potential for rainy ( $\mathbf{(})$ and dry ( $\square$ ) seasons in monocropped rubber tree ( $P$ - clone $P B 235$ and $G$ - clone $G T 1)$, monocropped coffee $(C)$, alley cropping coffee/ rubber tree (Cr and $\mathrm{Sr}$ ), hedge-row intercropping coffee/ rubber tree (Cm and $\mathrm{Sm})$. Bars correspond to the mean ( \pm standard error) of 20 replications.

Observou-se menor variação do potencial hídrico ao meio-dia em relação aos valores obtidos antes do amanhecer nas seringueiras que nos cafeeiros, dentro da mesma estação. Esse comportamento pode estar associado a um uso mais eficiente da água e também à característica do sistema radicular dessa espécie, que é mais agressivo e hábil em explorar o solo em profundidade (FURIA, 2000).

Em relação à fotossíntese líquida e à condutância estomática (Figura 3), na época chuvosa verificamse diferenças significativas entre as espécies, sendo em geral os maiores valores observados nas seringueiras, enquanto na estação seca tanto a fotossíntese quanto a condutância estomática são semelhantes entre as espécies. Para a seringueira, em geral, tanto a fotossíntese quanto à condutância estomática foram maiores durante a época chuvosa em relação à época seca, com diferenças significativas para o clone GT1 e consórcio renque (Figura 3). Contudo, nos cafeeiros os valores de fotossíntese na estação seca são superiores aos da época chuvosa, com diferenças significativas nos cafeeiros do consórcio tipo margem.

Como há um padrão de comportamento semelhante para a fotossíntese e condutância estomática, podese sugerir um controle das trocas gasosas por fatores estomáticos, que é mais nítido nas seringueiras. A diferença sazonal entre os fatores de regulação das trocas gasosas nos cafeeiros aponta maior controle estomático na época chuvosa que na seca. Um comportamento semelhante foi observado por Silva et al. (2004), que avaliaram as trocas gasosas de cafeeiros em monocultivo durante a época chuvosa e a época seca.

A tendência de a taxa fotossintética ser menor na época chuvosa para os cafeeiros pode confirmar que um microclima caracterizado por menores níveis de radiação, menor demanda evaporativa da atmosfera e temperaturas mais amenas pode favorecer a fotossíntese dessa cultura. Resultados semelhantes foram observados por outros autores, citados por Fournier (1988) e por Da Matta (2004), que verificaram maiores taxas fotossintéticas em ambientes com menor radiação.

Deve-se ressaltar que o estado de desenvolvimento dos plantios estudados neste trabalho não caracteriza uma condição de sombreamento, que poderia reduzir a fotossíntese do cafeeiro (Figura 1), como constatado em trabalhos realizados com sombreamento de cafeeiros por seringueira (NASCIMENTO, 2002) e por guandu (MORAIS et al., 2003). Desse modo, os resultados são um efeito das variações sazonais e não do tipo de cultivo determinando uma condição de sombreamento que afete as trocas gasosas. No entanto, Silva et al. (2004), avaliando a fotossíntese de Coffea arabica L. em monocultivo, durante a época seca e a época chuvosa em Viçosa,

R. Árvore, Viçosa-MG, v.30, n.2, p.197-206, 2006 
MG, observaram maiores taxas fotossintéticas durante a época de chuva. A divergência entre os resultados do presente estudo e os trabalhos de Silva et al., citados anteriormente, pode ser atribuída às diferenças na metodologia de avaliação das trocas gasosas, em que as medidas foram realizadas com controle da intensidade luminosa $\left(850 \mu \mathrm{mol} . \mathrm{m}^{-2} \mathrm{~s}^{-1}\right)$ às $8 \mathrm{~h}$.

A eficiência fotoquímica do fotossistema II (Figura 3), avaliada pela razão Fv/Fm, nas seringueiras apresentou valores significativamente maiores na estação chuvosa $(0,70-0,80$ na época chuvosa e cerca de 0,60 na época seca), exceto nas plantas cultivadas no sistema renque (0,60 em ambas as épocas). Nos cafeeiros, não houve diferenças entre as estações, apresentando valores próximos de 0,70 . No entanto, na época seca a razão Fv/Fm foi significativamente superior nessa espécie em relação à seringueira.

De acordo com Bolhar-Nordenkampf et al. (1989), valores da razão Fv/Fm entre 0,75 e 0,85 são característicos de plantas em ótimas condições de desenvolvimento. Os menores valores da relação, apresentados pelas seringueiras durante a estação seca, podem indicar maior suscetibilidade do fotossistema II dessa espécie, confirmando que menores temperaturas prejudicam o seu desenvolvimento, resultados esses que concordam com os de Ortolani et al. (1985).

A variação diurna das características microclimáticas em um dia típico da estação chuvosa (17/03/2001 precipitação no dia anterior: $47,5 \mathrm{~mm}$ ) e um da estação seca (24/06/2001) estão apresentados na Figura 4. Em geral, março se caracterizou por valores mais elevados de DFFFAe DPV (1.050 a $\left.2.300 \mu \mathrm{mol} \mathrm{m}^{-2} \mathrm{~s}^{-1} ; 2,2 \mathrm{a} 4,7 \mathrm{kPa}\right)$, em comparação com junho (300 a $1700 \mu \mathrm{mol} \mathrm{m}^{-2} \mathrm{~s}^{-1} ; 1,9$ a $3,0 \mathrm{kPa}$ ).

Na estação chuvosa (17/03), o potencial hídrico ao amanhecer $(6 \mathrm{~h})$ manteve-se superior a - 0,50 MPa em todos os tratamentos, indicando ótimas condições de disponibilidade de água no solo, enquanto na estação seca (24/06) os valores são menores que - 0,70 MPa, observando menores valores nos cafeeiros em consórcio e as seringueiras em monocultivo (Tabela 1). Tal constatação pode ser atribuída à área de solo exposto à radiação solar em cada sistema de cultivo; função dos diferentes espaçamentos entre plantas. Observaou-se, nessa fase de desenvolvimento dos sistemas de cultivo, solo exposto e sujeito a maior dessecamento nos sistemas consorciados e no monocultivo de seringueira, em comparação com o monocultivo de cafeeiros.
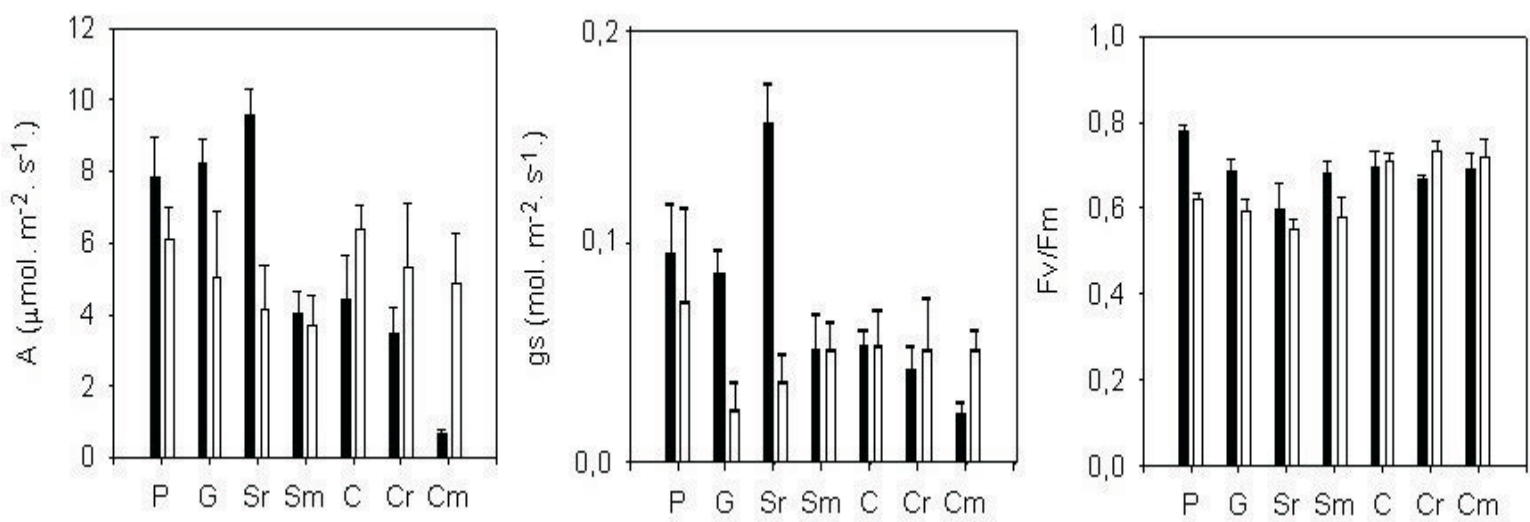

Figura 3 - Valores médios sazonais da fotossíntese líquida (A), condutância estomática (gs) e eficiência fotoquímica do fotossistema II (Fv/Fm) referentes à estação chuvosa (ם) e à estação seca ( $\square)$, às 12 horas, em plantas de seringueira em monocultivo (P - clone PB 235 e G - clone GT1), café em monocultivo (C), seringueira e café consorciados em renque ( $\mathrm{Sr}$ e $\mathrm{Cr}$ ) e seringueira e café consorciados em margem ( $\mathrm{Sm}$ e $\mathrm{Cm}$ ). Cada ponto corresponde à média ( \pm erro-padrão) de 20 observações.

Figure 3 - Seasonal mean midday net photosynthesis (A), stomatal conductance ( $g s)$ and $F v / F m$ fluorescence ratio for rainy $(\square)$ and dry $(\square)$ seasons in monocropped rubber tree ( $P$ - clone PB 235 and $G$ - clone GT1), monocropped coffee $(C)$, alley cropping coffee/ rubber tree (Cr and $\mathrm{Sr}$ ), hedge-row intercropping coffee/ rubber tree (Cm and Sm). Bars correspond to the mean ( \pm standard error) of 20 replications.

R. Árvore, Viçosa-MG, v.30, n.2, p.197-206, 2006

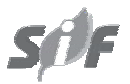




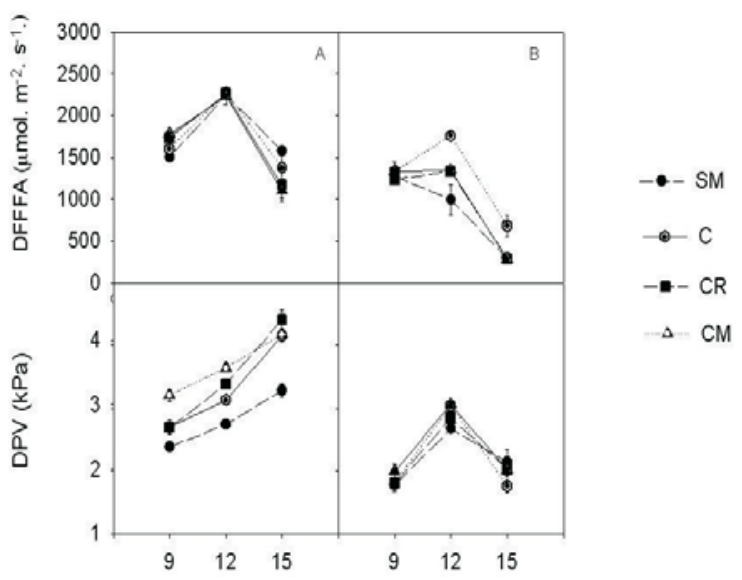

Figura 4 - Variação diurna da densidade de fluxo de fótons fotossinteticamente ativos (DFFFA) e déficit de pressão de vapor (DPV) em plantas de seringueira em monocultivo (SM $\bullet$ ) e café em monocultivo (CO), consórcio café/seringueira tipo renque (CR⿴) e consórcio café/seringueira tipo margem (CM $\triangle$ ), na estação chuvosa, A (17/03/2001) e na estação seca, B (24/06/2001), em diferentes horários. Cada ponto corresponde à média \pm erro-padrão de oito observações.

Figure 4-Daily course of photosynthetic photon flux density (DFFFA) and vapor pressure deficit (DPV) in monocropped rubber tree tree (SM๑), monocropped coffee (CO), alley cropping coffee/ rubber tree (CR $\mathbf{\square})$, hedge-row intercropping coffee/ rubber tree (CM $\triangle$ ). Bars correspond to the mean ( \pm standard error) of 8 replications.

O potencial hídrico obtido ao meio-dia apresentou valores superiores para 17/03 em relação aos de 24/ 06. Dentre os tratamentos, a maior variação em ambas as datas ocorreu nos cafeeiros, como observado na análise dos dados médios sazonais (Figura 2).

Os menores valores de potencial hídrico observados ao meio-dia na estação seca $(-1,03$ a -1,43 MPa) não são limitantes à seringueira (BRUNINI e CARDOSO, 1997). Entretanto, valores menores que -2,0 MPa são prejudiciais ao cafeeiro, uma vez que causam a redução da condutância estomática e, conseqüentemente, das taxas de fotossíntese (KUMAR e TIESZEN, 1980; LIMA et al., 2002).

A análise da variação diurna da fotossíntese indicou redução ao longo do dia em todos os tratamentos, nas duas datas de avaliação (Figura 5AB). Verificou-se, no dia 17/03 (Figura 5A), que em geral existe uma resposta inversa da fotossíntese ao DPV, evidenciando, mais uma vez, o controle estomático das trocas gasosas nessa época do ano no cafeeiro (SILVA et al., 2004) e na seringueira. Em 24/06 (Figura 5B), as respostas de trocas gasosas dos tratamentos parecem estar mais associadas à disponibilidade de radiação do que ao DPV.

Semelhantemente às médias sazonais, observaram-se valores superiores para fotossíntese das seringueiras em relação aos cafeeiros no dia da estação chuvosa (17/03). Na estação seca, os valores de fotossíntese dos cafeeiros superaram os das seringueiras, mesmo com a queda que ocorreu às 15 h (Figura 5B). Mais uma vez, os cafeeiros consorciados parecem responder melhor a condições de baixa radiação e menor DPV, condições características do início da manhã e de dias da estação seca. Freitas et al. (2003), estudando o comportamento fisiológico de diferentes cultivares de café, observaram melhores respostas de trocas gasosas em menores níveis de radiação.

Tabela 1 - Potencial hídrico foliar ao amanhecer e ao meiodia solar em seringueiras (P - clone PB 235 e G - clone GT1) e cafeeiros (C) em monocultivo, seringueira e café consorciados em renque $(\mathrm{Sr}$ e Cr) e seringueira e café consorciados em margem $(\mathrm{Sm}$ e $\mathrm{Cm})$, referentes às datas de avaliação 17/03/2001 e 24/06/2001

Table 1 - Predawn and midday leaf water potential in monocropped rubber tree ( $P$ - clone PB 235 and $G$ - clone GT1), monocropped coffee $(C)$, alley cropping coffeel rubber tree (Cr and $\mathrm{Sr}$ ), hedgerow intercropping coffee/rubber tree (Cm and $\mathrm{Sm})$. The measurements were taken on 17/03/2001e $24 / 06 / 2001$

\begin{tabular}{ccccc}
\hline \multirow{2}{*}{ Tratamento } & \multicolumn{3}{c}{ Potencial Hídrico Foliar (-MPa) } \\
\cline { 2 - 5 } & \multicolumn{2}{c}{$17 / 03 / 2001$} & \multicolumn{2}{c}{$24 / 06 / 2001$} \\
\cline { 2 - 5 } & 06 & 12 & 06 & 12 \\
horas & horas & horas & horas \\
\hline $\mathrm{G}$ & $0,38 \mathrm{ab}$ & $0,32 \mathrm{~d}$ & $0,97 \mathrm{ab}$ & $1,03 \mathrm{c}$ \\
$\mathrm{P}$ & $0,57 \mathrm{a}$ & $0,38 \mathrm{~d}$ & $1,17 \mathrm{a}$ & $1,43 \mathrm{c}$ \\
$\mathrm{C}$ & $0,35 \mathrm{ab}$ & $1,50 \mathrm{~b}$ & $1,03 \mathrm{a}$ & $2,15 \mathrm{~b}$ \\
$\mathrm{Sr}$ & $0,27 \mathrm{~b}$ & $0,38 \mathrm{~d}$ & $0,72 \mathrm{bc}$ & $1,30 \mathrm{c}$ \\
$\mathrm{Cr}$ & $0,30 \mathrm{~b}$ & $1,83 \mathrm{~b}$ & $1,13 \mathrm{a}$ & $2,23 \mathrm{~b}$ \\
$\mathrm{Sm}$ & $0,25 \mathrm{~b}$ & $1,00 \mathrm{c}$ & $0,68 \mathrm{c}$ & $1,28 \mathrm{c}$ \\
$\mathrm{Cm}$ & $0,35 \mathrm{ab}$ & $2,62 \mathrm{a}$ & $1,00 \mathrm{a}$ & $2,87 \mathrm{a}$ \\
\hline
\end{tabular}

*Médias seguidas da mesma letra na vertical não diferem estatisticamente entre si, pelo teste de Tukey a $5 \%$ de probabilidade.

* Means followed by the same letter in the columns do not differ significantly by Tukey's test at $5 \%$ of probability level.

R. Árvore, Viçosa-MG, v.30, n.2, p.197-206, 2006 


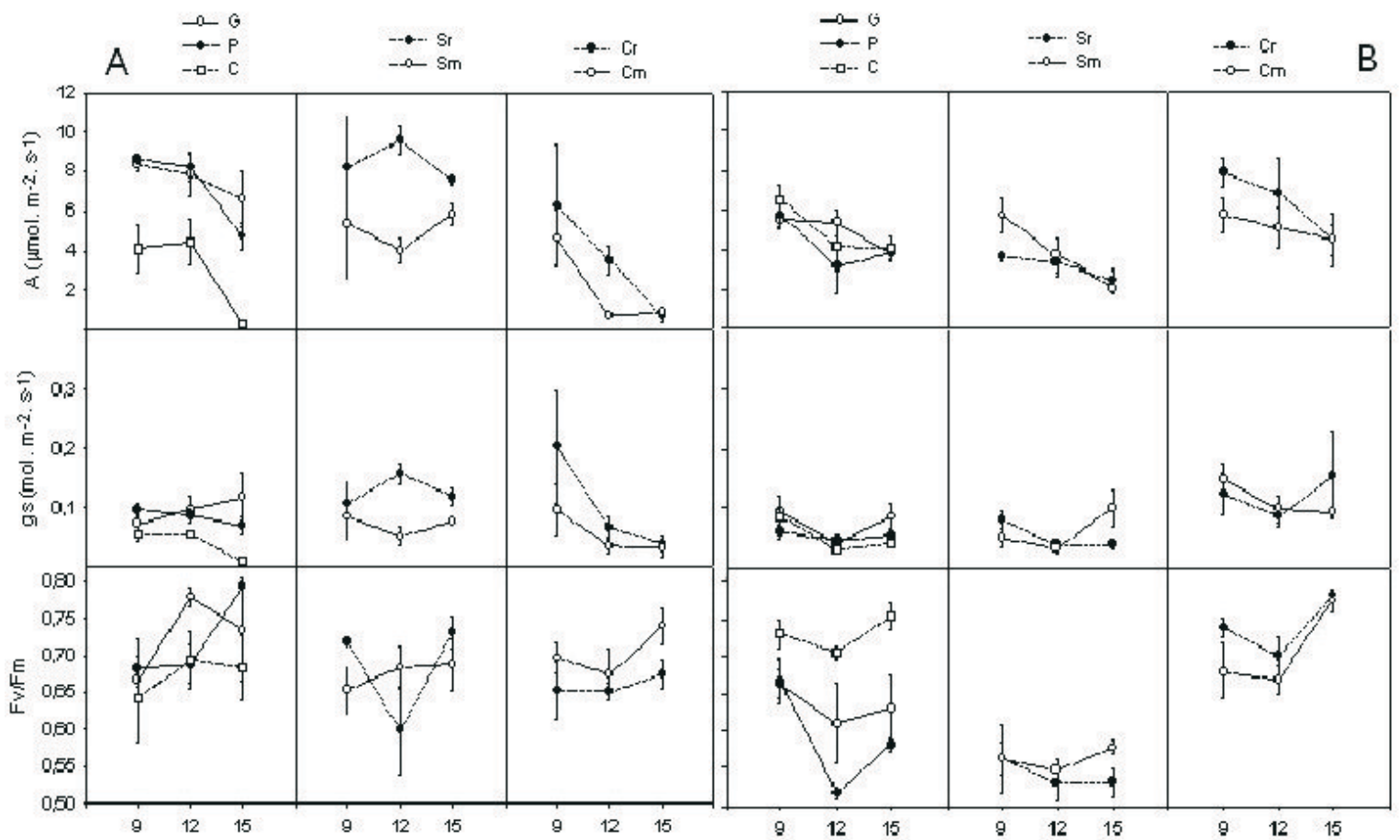

Figura 5 - Variação diurna da fotossíntese líquida (A), condutância estomática (gs) e eficiência fotoquímica do fotossistema II (Fv/Fm) em plantas de seringueira em monocultivo clone GT1 (G-O) e clone PB235 (P-๑), em consórcio tipo renque (Sr- $)$ e tipo margem (Sm-O) e cafeeiros em monocultivo $(\mathrm{C}-\square)$, em consórcio tipo renque $(\mathrm{Cr}$ -) e tipo margem (Cm-O) em 17/03/2001 (A) e 24/06/2001 (B). Cada ponto corresponde à média \pm erro-padrão de quatro observações.

Figure 5 -Daily course of net photosynthesis (A), stomatal conductance ( $g s)$ and $F v / F m$ fluorescence ratio in monocropped rubber tree clone PB $235(\mathrm{P}-\bullet)$ and clone $G T 1(G-O)$, alley cropping $(S r-\bullet)$, and hedge-row intercropping ( $\mathrm{Sm}-\mathrm{O}$ ) and monocropped coffee $(\mathrm{C}-\square)$, alley cropping (Cr-๑), and hedge-row intercropping (Cm-O) on 17/ $03 / 2001$ (A) and 24/06/2001 (B). Points correspond to the mean ( \pm standard error) of 4 replications.

Os resultados da razão Fv/Fm no dia 17/03 (Figura 5A) de modo geral foram maiores nas seringueiras. Esses resultados indicam para o cafeeiro uma possível condição de estresse por excesso de radiação, que pode afetar o fotossistema II. A redução no valor da razão ao meio-dia (especialmente para a seringueira em consórcio renque) provavelmente também está associada à elevada radiação. Entretanto, esses resultados não explicam as reduções da fotossíntese, sendo essa variável mais controlada pela condutância estomática.

As plantas de seringueira apresentaram menor razão Fv/Fm, em comparação com os cafeeiros no dia 24/06 (Figura 5B), sendo observadas diferenças entre as espécies nos horários de avaliação. Os valores da razão Fv/Fm nessa data para a seringueira indicam que, nesse momento do seu desenvolvimento, é uma planta sensível à fotoinibição. Apesar de ser uma espécie heliófita, a introdução em uma região com características distintas daquelas do "habitat" onde se originou pode ter contribuído para tal comportamento (MACEDO, 2000)

\section{CONCLUSÃO}

As avaliações das trocas gasosas apontaram, em geral, para a seringueira maior taxa de fotossíntese, enquanto um microclima caracterizado por níveis de radiação mais baixos, uma menor demanda evaporativa da atmosfera e temperaturas mais amenas, que são favoráveis ao processo fotossintético do cafeeiro.

R. Árvore, Viçosa-MG, v.30, n.2, p.197-206, 2006 
Os resultados obtidos não permitiram evidenciar efeitos dos sistemas de cultivo no comportamento das plantas estudadas, o que pode ser associado à fase de desenvolvimento dos sistemas consorciados. Contudo, foi observado que o consórcio tipo renque se apresentou mais favorável ao desenvolvimento das seringueiras e às características fisiológicas dos cafeeiros.

\section{AGRADECIMENTOS}

Os autores agradecem ao auxílio do PNP\&D CAFÉ/ EMBRAPA, o que possibilitou a realização do presente trabalho.

\section{REFERÊNCIAS BIBLIOGRÁFICAS}

BARRADAS, V. L.; FANJUL, L. Microclimate caracterization of shaded and open grown coffee (Coffea arabica L.) plantation in Mexico. Agricultural and Forest Meteorology, v.38, n.1-3, p. 101-112, 1986.

BOLHAR-NORDENKAMPF, H. R. et al. Chlorophyll flourescence as a probe of the photosynthetic competence os leaves in the field: a review of current instrumentation. Functional Ecology, v. 3, p. 497-514. 1989.

BRASIL. Ministério da Agricultura e Reforma Agrária. Secretaria Nacional de Irrigação. Departamento Nacional de Meteorologia. Normais Climatológicas 1961-1990. Brasília, 1992. 84p.

BRUNINI, O.; CARDOSO, M. Efeito do déficit hídrico no solo sobre o comportamento estomático e potencial da água em mudas de seringueira. Pesquisa Agropecuária Brasileira, v. 33, n. 7, p. $32-38,1998$.

Da MATTA, F. M. Ecophysiological constraints on the production of shaded and unshaded coffee: a review. Field Crops Research, v. 86 , p. 99 - 114. 2004.

FREITAS, R. B. et al. Influência de diferentes níveis de sombreamento no comportamento fisiológico de cultivares de café (Coffea arabica L.). Ciência e Agrotecnologia, v.27, n.4, p.804-810, 2003.

FONTES, R. E. Estudo Econômico da Cafeicultura no sul de Minas Gerais. 2001. 94 f. Dissertação (Mestrado em Economia Rural). Universidade Federal de Lavras, Lavras, 2001.
FOURNIER, L. A. El cultivo del cafeto (Coffea arabica L.) al sol o a la sombra: un enfoque agronomico y ecofisiologico. Agronomia Costarricense, v.12, n.1, p.131-146, 1988.

FURIA, L. R. R. Relações ecológicas entre as culturas de milho (Zea mays) e seringueira (Hevea brasiliensis) em um sistema agroflorestal. 2000. 103f.

Dissertação (Mestrado em Engenharia Florestal). Escola Superior de Agricultura Luiz de Queiroz, Piracicaba, 2000.

INSTITUT DE RECHERCHES SUR LE CAOUTCHOUC. Rapport general 1990. Paris: IRCA/CIRAD, 1992. 219 p.

JARAMILLO-ROBLEDO, A.; VALENCIAARISTIZABAL, G. Los elementos climáticos y el desarrollo de Coffea arabica L., en Chinchina, Colombia. Cenicafé, v.31, n.4, p.127-143, 1980.

KUMAR, D.; TIESZEN, L. L. Photossynthesis in Coffea arabica. II. Effects of water stress.

Experimental Agricultura, v. 16, p. 21-27, 1980.

LIMA, A. L. S. et al. Photochemical responses and oxidative stress in two clones of Coffea canephora under water deficit conditions. Environmental and Experimental Botany, v. 47, p. 239-247. 2002.

MACEDO, R. L. G.; VENTORIN, N.; CARVALHO, A. J.; DANTAS, F. W. F. Efeitos da colheita do café sobre o estabelecimento da seringueira introduzida em sistemas agroflorestais com o cafeeiro em Lavras-MG. In: SIMPÓSIO INTERNACIONAL SOBRE ECOSSISTEMAS FLORESTAIS, 5., FOREST 2000, Porto-SeguroBahia, 2000. Anais... Rio de Janeiro: Biosfera, 2000. 2p.

MONTEITH, J. L.; ONG, C. K.; CORLETT, J. E. Microclimatic interations in agroforestry systems. In.: JARVIS, P.G. (Ed.). Agroforestry: principles and pratice. Amsterdan: Elsevier, 1991. 336p.

MORAIS, H. et al. Características fisiológicas e de crescimento de cafeeiro sombreado com guandu e cultivado a pleno sol. Pesquisa Agropecuária Brasileira, v. 38, n. 10, p.1131-1137, 2003.

R. Árvore, Viçosa-MG, v.30, n.2, p.197-206, 2006 
ORTOLANI, A.A. Aptidão climática para cultura da seringueira em Minas Gerais. Informe Agropecuário, v.11, n.121, p.8-12, 1985.

PEETERS, L. Y. K. et al. Coffee production, timber, and firewood in traditional and Inga-shaded plantations in Southern Mexico. Agriculture, Ecosystems and Environment, v.95, p.481-493, 2003.

PEREIRA, A. V. et al. Sistemas agroflorestais de seringueira com cafeeiro. Planaltina, DF: Embrapa, 1998. 77p. (Documentos, 70).

PEREIRA, J. P. et al. Desenvolvimento vegetativo da seringueira em sistema agroflorestal com cafeeiro em fase terminal. In: SIMPÓSIO INTERNACIONAL SOBRE ECOSSISTEMAS FLORESTIAS, 6., FOREST 2000, Porto Seguro, 2000. Anais... Rio de Janeiro, Biosfera, 2000. 4p.
RENA, A. B. et al. Plantios adensados: aspectos morfológicos, ecofisiológicos, fenológicos e agronômicos. Informe Agropecuário, v. 19, n. 193, p. 61-70, 1998.

SANTOS, A. J. et al. Viabilidade econômica do sistema agroflorestal Grevílea x Café na região norte do Paraná. Cerne, v.6, n.1, p.089-100, 2000.

SCHALLER, M. et al. Species and site characteristics that permit the association of fast-growing trees with crops: the case of Eucalyptus degulata as coffee shade in Costa Rica. Forest Ecology and Management, v.175, p. 205-215, 2003.

SILVA, E. A. et al. Seasonal changes in vegetative growth and photosynthesis of Arabica coffee trees. Fields Crops Research, 2004. (Article in press).

VENEZIANO, W. et al. Associação da seringueira com a cultura do cafeeiro no Estado de Rondônia. In: CONGRESSO BRASILEIRO SOBRE SISTEMAS AGROFLORESTAIS, 1., Porto Velho, 1994. Anais... Colombo: EMBRAPA-CNPF, 1994. v.1.p.121-133. 